\title{
Towards improved accuracy in chlorine isotope analysis: synthesis routes for in-house standards and characterization via complementary mass spectrometry methods
}

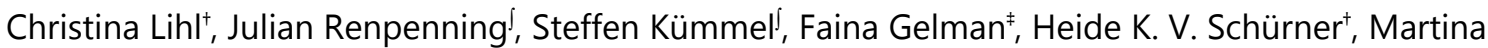
Daubmeier ${ }^{\dagger}$, Benjamin Heckel ${ }^{\bar{\top}}$, Aileen Melsbach ${ }^{\dagger}$, Anat Bernstein§, Orfan Shouakar-Stash", Matthias Gehre', Martin Elsner ${ }^{\star+\bar{\top}}$

+ Institute of Groundwater Ecology, Helmholtz Zentrum München, Ingolstädter Landstraße 1, 85764 Neuherberg, Germany

I Department of Isotope Biogeochemistry, Helmholtz Centre for Environmental Research - UFZ, Permoserstraße 15, 04318 Leipzig, Germany

‡ Geological Survey of Israel, 32 Yeshayahu Leibowitz St., 9692100 Jerusalem, Israel

$\bar{\top}$ Chair of Analytical Chemistry and Water Chemistry, Technical University of Munich, Marchionistraße 17, 81377 München, Germany

$\S$ Zuckerberg Institute for Water Research, Department of Environmental Hydrology and Microbiology, Ben-Gurion University of the Negev, 84990 Sede Boqer, Israel

" Department of Earth Sciences, University of Waterloo, 200 University Avenue, Waterloo, Ontario, Canada N2L $3 G 1$

*Corresponding Author: Phone: +49 89/2180-78231. E-mail: m.elsner@tum.de

Summary:

3 Pages, 3 Schemes, 1 Table 
Scheme S1: Illustrating the workflow of the isotopic characterization of CT16, TCE-2 and MeCl via GCMC-ICPMS.

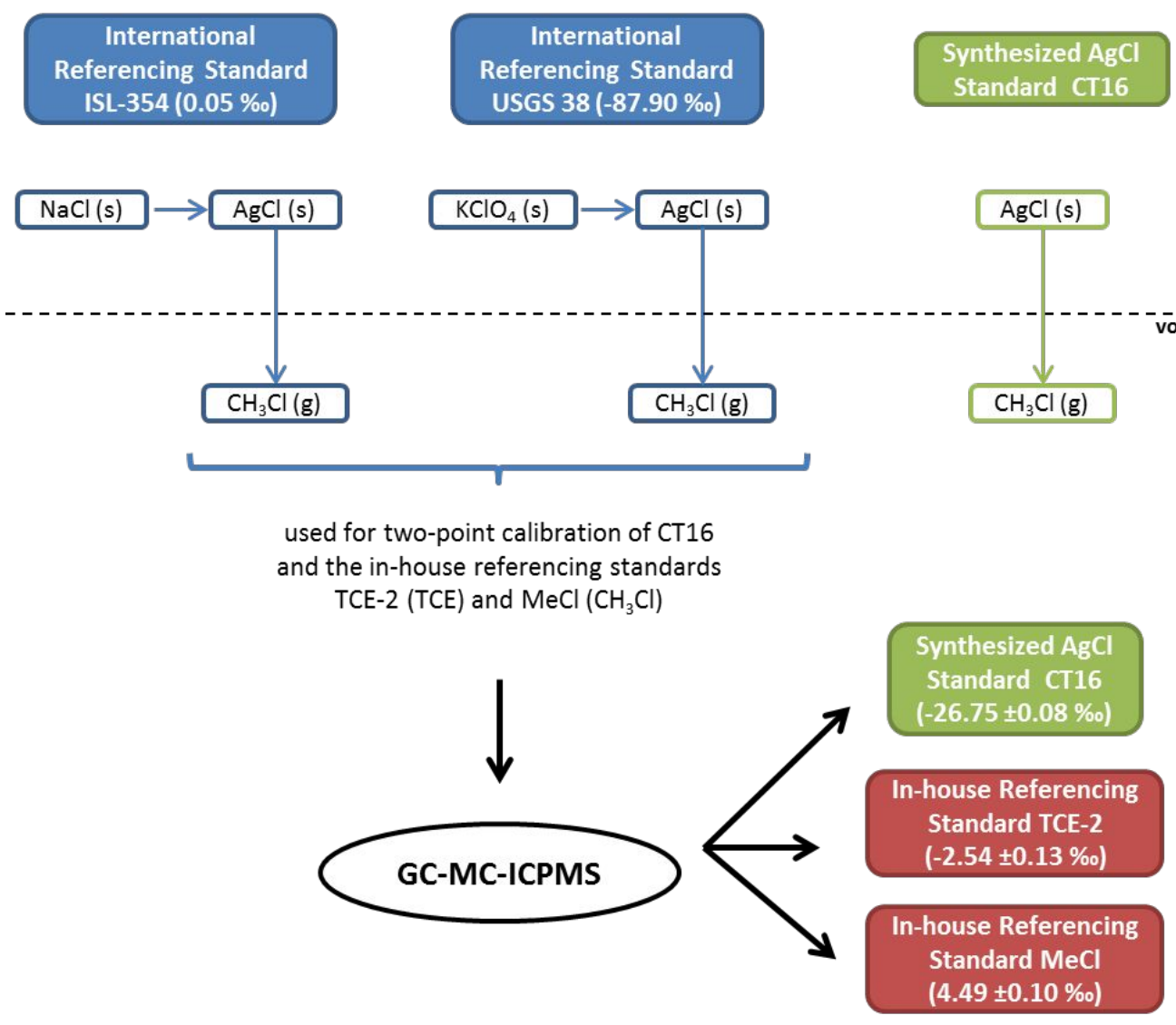

Scheme S2: Illustrating the workflow of the isotopic characterization of Atrazine, Acetochlor and SMetolachlor working standards via GC-MC-ICPMS.

\section{In-house Referencing \\ Standard TCE-2 \\ $(-2.54 \pm 0.13 \%$ o)}

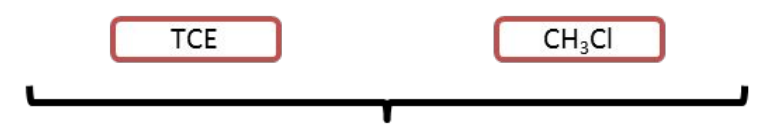

used for two-point calibration of the working standards for Atrazine, Acetochlor and S-Metolachlor

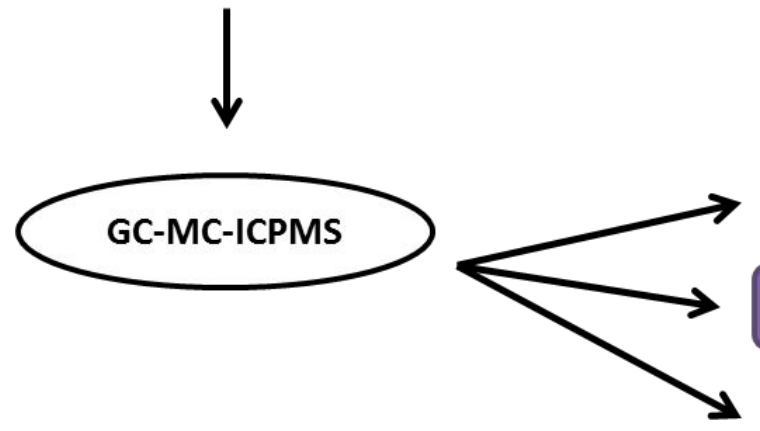

In-house Referencing

Standard $\mathrm{MeCl}$

$(4.49 \pm 0.10 \%$ )

Acetochlor

Standards

S-Metolachlor

Standards

Atrazine

Atrazine 
Scheme S3: Illustrating the workflow of the isotopic characterization of CT16 via GC-IRMS.
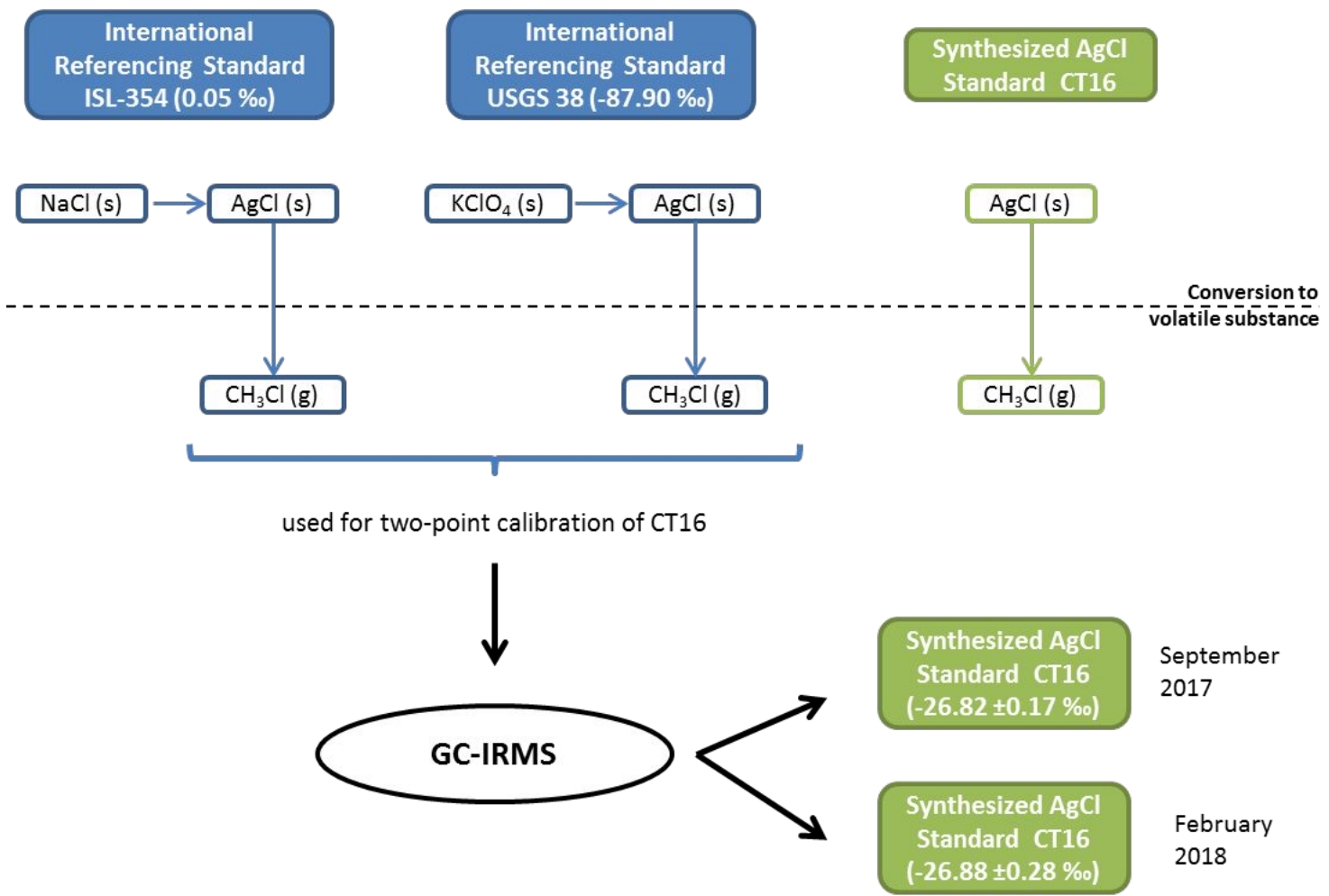

Table S1: List of purchased semi-volatile substances, which were calibrated against the in-house referencing standards TCE-2 and $\mathrm{MeCl}$ to be used as working standards in the future.

\begin{tabular}{llll}
\hline $\begin{array}{l}\text { Working } \\
\text { Standard }\end{array}$ & Substance & Supplier & $\mathbf{\delta}^{37} \mathbf{C l} \pm \mathbf{S D}$ [\%o] \\
\hline ATR \#4 & Atrazine & Oskar Tropitzsch & $-0.89 \pm 0.24$ \\
ATR \#11 & Atrazine & Riedel-de Haën & $3.59 \pm 0.37$ \\
ATR_A & Atrazine & Oskar Tropitzsch & $-0.89 \pm 0.05$ \\
ACETO_A & Acetochlor & Chemos & $-0.12 \pm 0.16$ \\
METO_A & S-Metolachlor & Oskar Tropitzsch & $-0.01 \pm 0.12$ \\
METO_B & S-Metolachlor & Chemos & $-2.75 \pm 0.09$ \\
\hline
\end{tabular}

*SD = standard deviation 